\title{
A database for semantic, grammatical, and frequency properties of the first words acquired by Italian children
}

\author{
PASQUALE RINALDI \\ Institute for Cognitive Sciences and Technologies, CNR, Rome, Italy \\ LAURA BARCA \\ Institute for Cognitive Sciences and Technologies, CNR, Rome, Italy \\ and University of Rome "La Sapienza," Rome, Italy \\ and \\ CRISTINA BURANI \\ Institute for Cognitive Sciences and Technologies, CNR, Rome, Italy
}

\begin{abstract}
The CFVlexvar.xls database includes imageability, frequency, and grammatical properties of the first words acquired by Italian children. For each of 519 words that are known by children 18-30 months of age (taken from Caselli \& Casadio's, 1995, Italian version of the MacArthur Communicative Development Inventory), new values of imageability are provided and values for age of acquisition, child written frequency, and adult written and spoken frequency are included. In this article, correlations among the variables are discussed and the words are grouped into grammatical categories. The results show that words acquired early have imageable referents, are frequently used in the texts read and written by elementary school children, and are frequent in adult written and spoken language. Nouns are acquired earlier and are more imageable than both verbs and adjectives. The composition in grammatical categories of the child's first vocabulary reflects the composition of adult vocabulary. The full set of these norms can be downloaded from www.psychonomic.org/archive/.
\end{abstract}

In this study, we analyze semantic, grammatical, and frequency characteristics of the first words acquired by Italian children (Child's First Vocabulary, or CFV), drawn from the Italian version (Caselli \& Casadio, 1995) of the MacArthur Communicative Development Inventory (CDI; Fenson et al., 1993). The CDI is an instrument for the collection of reliable information on early language development - that is, in the age range of 8-30 months. It is organized into two distinct questionnaires. The first, Gestures and Words (ages 8-16 months), is used for the collection of information on the comprehension and production of words and on the use of communicative gestures. The second questionnaire, Words and Phrases (ages 16-30 months), is used to collect information on word production and on grammatical, syntactic, and morphological competence. The questionnaires

This work was supported by a Grant to Virginia Volterra from the EUROCORES program, The Origin of Man, Language and Languages, and by MIUR-FIRB Grant RBAU01LE9P to C.B. Our most grateful thoughts go out to Elizabeth Bates, who enthusiastically supported this work, giving us invaluable comments and insights. We will miss her warmth and friendship immensely. We thank Lisa Saskia Arduino and Laura Menenti for valuable comments and suggestions. Correspondence concerning this article should be addressed to C. Burani, Istituto di Scienze e Tecnologie della Cognizione, CNR, viale Marx, 15, Roma 00137, Italy (e-mail: c.burani@istc.cnr.it). are compiled by parents on the basis of written instructions. The score for each child can be converted into a percentile score and compared with the scores of other children of the same age. This instrument has been translated and adapted for use with children of different cultures and languages.

In preceding studies, in which norms for age of acquisition were derived from subjective estimates of adults, it was found that words acquired early have highly imageable referents and are very frequent in the written lexicon of children in primary school and in both the written and spoken lexicons of adults (for the case of Italian, see Barca, Burani, $\&$ Arduino, 2002). The main goal of the present study was to identify the imageability and frequency properties of the words in the $\mathrm{CFV}$, and to assess whether the correlations that hold among the variables for these words acquired very early (before 30 months of age) are similar to the correlations that have been described for other word samples. The second goal was to verify if the CFV has the same proportions of nouns, verbs, and adjectives as are found in adult vocabulary. Finally, we compared the age of acquisition, imageability, and frequency characteristics of different grammatical categories (nouns, verbs, and adjectives).

\section{The Child's First Vocabulary (CFV) Database ${ }^{1}$}

In the CFVlexvar.xls database, we included the words listed in the Words and Phrases questionnaire (16-30 
months) of the Italian version of the CDI (Caselli \& Casadio, 1995), except for words from the following categories: sounds and voices of nature, routines, pronouns, articles and quantifiers, auxiliary and modal verbs, conjunctions, and adverbs. These categories were excluded because they either contained few words or did not readily lend themselves to analysis with the variables used here. Furthermore, we excluded some compound words because they were not included in the frequency lexicons we considered, as well as a few words that have clearly different meanings for adults than they normally do for children.

For each of the 519 words in the CFVlexvar.xls database, values of age of acquisition, frequency in the written lexicon of primary school children, and frequencies in both the spoken and written lexicons of adults were included, and new imageability values were obtained. The selected variables correspond to those that in most studies are found to have strong correlations with age of acquisition. The CFVlexvar.xls database (Excel 5.0) is a useful tool for research on lexical processing and provides an instrument for the study of semantic, grammatical, and frequency characteristics of the first words acquired by Italian children.

\section{Variables}

Grammatical category. For each word, the grammatical category of Noun (N), Verb (V), or Adjective (Adj) is included.

Age of acquisition (\%CFV) is usually defined as the estimated age at which a word and its meaning were first learned, either in the auditory or in the written modality (Morrison, Chappell, \& Ellis, 1997). Our \%CFV values are derived from published norms for the Italian version of the CDI (Appendix E of Caselli \& Casadio, 1995), in which the percentage of children in the age range of 16-30 months that can produce the word is listed for each word. These percentage values could be considered an "objective" index of age of acquisition, assuming that the higher the percentage of children producing a certain word, the earlier that word is acquired (for other uses of the CDI norms as objective age of acquisition norms, see D'Amico, Devescovi, \& Bates, 2001; Szekely et al., in press). An objection could be raised in that the \%CFV values obtained in the CDI are still subjective estimates of age of acquisition, since they are provided by the parents of the children. ${ }^{2}$ However, a large number of studies on both the American and Italian versions of the questionnaire (see Fenson et al., 1994, and Devescovi \& Caselli, 2001, respectively) have demonstrated that estimates of age of acquisition derived from this instrument are strongly correlated with observations of children both at home and in the laboratory (for other "objective" methods for determining age of acquisition, see Brysbaert, 1996; Jorm, 1991; Morrison et al., 1997; Walley \& Metsala, 1992).

Imageability (IMAG) is defined as the ease and speed with which a target word evokes a mental image, a visual representation, a sound, or any other sensory experience (Cornoldi, 1974; Paivio, Yuille, \& Madigan, 1968). Our
IMAG values (means and $S D$ s) were obtained from subjective ratings (on a 7-point scale, with 1 corresponding to hardly imageable and 7 to highly imageable) given by 50 Italian university students (half males and half females) aged 20-30 years. The instructions were adapted from Barca et al. (2002). The words of the CFV were inserted into a larger list, which also contained less imageable fillers in order to obtain some variability in estimates.

Child written frequency (CWFq) was extracted from the lexicon constructed by Marconi, Ott, Pesenti, Ratti, \& Tavella (1994). The corpus includes a total of $1,000,000$ word tokens subdivided into two sections: 500,000 tokens were drawn from texts read by children in primary school (readers, fairy tales, school newspapers, comics, and textbooks aimed at children between the first and fifth grades), and the other 500,000 tokens were taken from essays written by first- to fifth-grade children. ${ }^{3}$

Adult written frequency (AWFq) was taken from a frequency count based on a corpus of 3,000,000 word tokens in written contemporary Italian texts (Laudanna, Thornton, Brown, Burani, \& Marconi, 1995).

Adult spoken frequency (ASFq) was taken from the frequency count by De Mauro, Mancini, Vedovelli, \& Voghera (1993), based on a corpus of 500,000 word tokens from samples of contemporary spoken Italian.

In Table 1, the variables included in the CFV database are listed, together with descriptive statistics for each variable. For all statistical analyses, the values of \%CFV, $\mathrm{CWFq}, \mathrm{AWFq}$, and ASFq were log transformed on the basis of the natural logarithm (1 + raw value).

\section{Correlations Among Variables}

Table 2 provides the Pearson correlation matrix of the variables. $\% \mathrm{CFV}$ has the highest correlation with IMAG $(r=.38)$, suggesting that the earlier a word is acquired, the more imageable it tends to be. \%CFV has significant correlations with the other variables as well-namely, with $\mathrm{CWFq}(r=.20), \operatorname{AWFq}(r=.19)$, and $\operatorname{ASFq}(r=.16)$, suggesting that the earlier a word is acquired, the more frequent it tends to be in both written and spoken language. These results confirm and extend those obtained by Barca et al. (2002), Bates, Burani, D’Amico, and Barca (2001), and D'Amico et al. (2001) on Italian nouns. It is worth noting that $\mathrm{CFV}$ words, being highly imageable and

Table 1

Descriptive Statistics on the Variables Included in the CFV Database

\begin{tabular}{lccccc}
\hline \multicolumn{1}{c}{ Variable } & Code & $M$ & $S D$ & Min & Max \\
\hline Age of acquisition & \%CFV & 40.22 & 18.01 & 2.59 & 97.15 \\
Imageability & IMAG & 5.51 & 0.83 & 2.70 & 6.70 \\
Child written frequency & CWFq & 317.57 & 784.57 & 0 & 10,775 \\
Adult written frequency & AWFq & 87.35 & 415.56 & 0 & 5,740 \\
Adult spoken frequency & ASFq & 179.99 & 352.88 & 0 & 3,100 \\
\hline
\end{tabular}

Note- $\%$ CFV is derived from published norms for the Italian version of the CDI (Appendix E in Caselli \& Casadio, 1995). IMAG is expressed on a 7-point scale. CWFq is based on 1,000,000 tokens; AWFq is based on 3,000,000 tokens; ASFq is based on 500,000 tokens. Raw values are reported. For a detailed description of the variables, see text. 
Table 2

Pearson Correlations

\begin{tabular}{|c|c|c|c|c|}
\hline Variable & $\% \mathrm{CFV}$ & IMAG & $\mathrm{CWFq}$ & AWFq \\
\hline IMAG & $.38 \dagger$ & - & & \\
\hline CWFq & $.20 \dagger$ & $-.20 \dagger$ & - & \\
\hline AWFq & $.19 \dagger$ & $-.20 \dagger$ & $.72 \dagger$ & - \\
\hline $\mathrm{ASFq}$ & $.16^{*}$ & $-.39 \dagger$ & $.72 \dagger$ & $.78 \dagger$ \\
\hline
\end{tabular}

Note- $\%$ CFV, age of acquisition; IMAG, imageability; CWFq, child written frequency; AWFq, adult written frequency; ASFq, adult spoken frequency. $* p<.001 . \quad{ }^{\dagger} p<.0001$.

very frequent, are all acquired early (before 30 months of age). Consequently, the latter strong correlations are particularly striking.

IMAG is correlated positively only with \%CFV. The correlations between IMAG and the various frequency measures are negative, apparently indicating that in both the written language of primary school children and the spoken and written language of adults, the words used most often have referents that are not readily imageable. However, it should be noted that this result is highly dependent on grammatical category. If correlations are calculated for nouns, adjectives, and verbs separately, a negative correlation between imageability and frequency measures is found for verbs only $\left(r=-.34^{*}\right.$ for IMAG/ CWFq; $r=-.34 *$ for IMAG/AWFq; $r=-.48^{*}$ for IMAG/ASFq), whereas adjectives and nouns show either nonsignificant or positive correlations between imageability and each of the various frequency measures. The high correlations between the various frequency measures indicate that the words in the CFV are written and read with similar frequency by children and by adults.

\section{Nouns, Verbs, and Adjectives}

It is known that in various languages the vocabularies of very young children are composed mainly of nouns, whereas verbs are few. Also, nouns are acquired before predicates (verbs and adjectives). This is the case for English, Italian, and Hebrew, but not for Mandarin Chinese (Tardif, Gelman, \& Xu, 1999) or Korean (Gopnik \& Choi, 1995). In a recent review, Colombo and Burani (2002) discussed possible reasons for this order of vocabulary acquisition in Italian as well as in other languages. According to various authors, the low conceptual complexity of nouns in comparison with verbs would lead to acquisition of the former before that of the latter. Nouns are claimed to be more natural than verbs: Nouns often refer to objects with directly perceivable properties, whereas verbs express mostly relational properties and are therefore more dependent on context and are more susceptible to changes, depending on the nouns to which they relate. Finally, it is claimed that it is principally production, rather than comprehension, that shows this developmental sequence of acquisition.

Regarding acquisition of the Italian language, the results are controversial. Most studies find the same order of acquisition as is found for English: Children learn nouns more easily than predicates (Caselli et al., 1995; Caselli,
Casadio, \& Bates, 1999; D’Amico, Devescovi, \& Bates, 2003; D’Odorico, Carubbi, Salerni, \& Calvo, 2001). However, Camaioni and Longobardi (1995) observed the speech production of 15 children in the age range of 16-20 months and found that only 1 child showed a clear predominance of nouns.

\section{Relative Proportion of Nouns, Verbs, and Adjectives in the CFV and in Two Vocabularies of the Italian Language}

The first words acquired by children comprise more nouns than verbs and adjectives. It may be asked whether this unequal numeric composition of the different grammatical categories is a general finding in the Italian language. To answer this question, we compared the composition in grammatical categories of the CFV with that of the Italian Basic Vocabulary (IBV), which contains the words that should be known by the end of compulsory education (De Mauro, 1991; Thornton, Iacobini, \& Burani, 1997), and with that of a more comprehensive Italian dictionary (ID; Zingarelli, 1987).

As can be seen in Figure 1, on the total of nouns, verbs, and adjectives, the percentages of nouns are very similar [between $64 \%$ and $69 \% ; \chi^{2}(2)=.26$, n.s.] in the three different vocabularies considered. Verbs have the same incidence in both the CFV and the IBV (about 20\%), but a somewhat lower incidence in the ID (about 13\%), although a $\chi^{2}$ test does not reveal statistically significant differences $\left[\chi^{2}(2)=1.94\right]$. Adjectives are also present in very similar proportions in the CFV and the IBV (between $12 \%$ and $15 \%$ ), whereas the percentage of adjectives is higher in the ID (23\%). Also, in the latter case a $\chi^{2}$ test does not show statistically significant differences $\left[\chi^{2}(2)=3.65.\right]$. From this, it can be concluded that words from the different grammatical categories are present in the CFV in proportions very similar to those found in the Italian language.

\section{Age of Acquisition of Nouns, Verbs, and Adjectives in the CFV}

To verify whether our data could supply further confirmation of the noun-verb order of acquisition, we performed a one-way analysis of variance (ANOVA) in which the factor was grammatical category, with three levels (nouns, verbs, and adjectives). The dependent variable was $\% \mathrm{CFV}$ (the percentage of children who produce a given word by 30 months of age).

The factor of grammatical category has a significant effect $[F(2,516)=14.88 ; p<.0001]$ : The average $\% \mathrm{CFV}$ differs depending on the grammatical category of the word (see Table 3 ). From post hoc comparisons (Duncan test), we found that children learn nouns before predicates ( $p<.001$ with respect to both verbs and adjectives), whereas there is no statistical difference within the predicate category - that is, between the acquisition of verbs and that of adjectives. Using an "objective" measure of age of acquisition derived from the CDI, Szekely et al. (in 


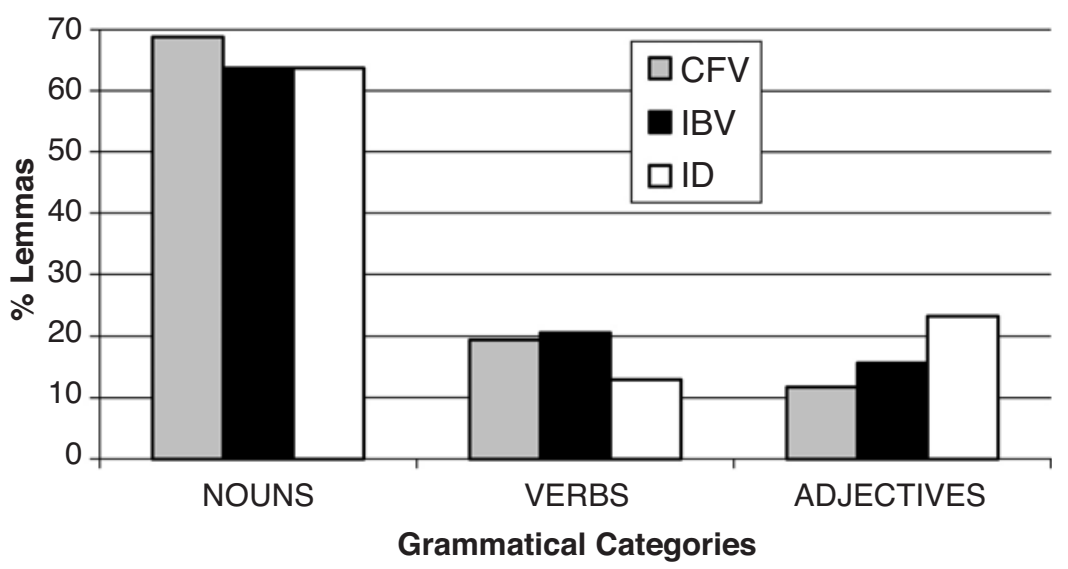

Figure 1. Comparison between the percentages of lemmas per grammatical category in the Child's First Vocabulary (CFV), the Italian Basic Vocabulary (IBV), and an Italian dictionary (ID). The IBV and ID also included other grammatical categories. The percentages of lemmas in each grammatical category as reported here are percentages on the total number of nouns, verbs, and adjectives.

press) found that, in a large sample of English words, the words referring to objects (nouns) are acquired before those referring to actions (verbs).

\section{Imageability of Nouns, Verbs, and Adjectives of the CVF}

To investigate the differences between the imageability values for the different grammatical categories, we ran a one-way ANOVA. The factor was again grammatical category, whereas the dependent variable was imageability. The effect of category was again significant $[F(2,516)=$ $337.51, p<.0001]$. Post hoc comparisons (Duncan test) showed that nouns are more imageable than both verbs and adjectives (both $p \mathrm{~s}<.0001$ ), whereas the difference in imageability between verbs and adjectives is only marginally significant $(p=.08)$. Therefore, the very first words acquired also tend to be more easily imageable when they are nouns than when they are verbs or adjectives (for the differences in imageability between nouns and verbs, see Chiarello, Shears, \& Lund, 1999).

\section{Frequency of Nouns, Verbs, and Adjectives}

To investigate whether nouns, verbs, and adjectives have different frequencies in the three lexicons considered here

Table 3

Number of Words $(N)$ per Grammatical Category, Mean Percentage of Children Producing Them (Age of Acquisition, or \%CFV), and Mean Values of Imageability (IMAG),

Child Written Frequency (CWFq), and Adult Written (AWFq) and Spoken (ASFq) Frequency

\begin{tabular}{lrcccrr}
\hline $\begin{array}{l}\text { Grammatical } \\
\text { Category }\end{array}$ & \multicolumn{1}{c}{$N$} & \%CFV & IMAG & CWFq & AWFq & ASFq \\
\hline Nouns & 357 & 43.02 & 5.95 & 199.31 & 28.43 & 158.85 \\
Verbs & 101 & 34.84 & 4.62 & 727.24 & 314.81 & 192.77 \\
Adjectives & 61 & 32.72 & 4.41 & 329.44 & 54.59 & 282.54 \\
\hline
\end{tabular}

Note-For each variable, raw values are reported.
(CWFq, AWFq, and ASFq; see Table 3), we ran three ANOVAs in which the factor was grammatical category and the dependent variables were the frequency counts in the three different lexicons. Grammatical category had a significant effect on frequency for all three lexicons $[\mathrm{CWFq}, F(2,516)=31.65, p<.0001 ; \mathrm{AWFq}, F(2,516)=$ $7.83, p<.001$; ASFq, $F(2,516)=39.86, p<.0001]$. This means that for all three frequency lexicons, the few predicates included among the earliest acquired words are used more often than the (many) nouns. This suggests that both in the child and the adult lexicons we tend to use a large number of nouns, many of them only sparsely, whereas we use a smaller number of verbs and adjectives often.

\section{Correlations Between Variables For Different Grammatical Categories}

We also calculated the correlations between the values of $\% \mathrm{CFV}$ and the other variables separately for the three grammatical categories (Table 4).

The highest correlation between \%CFV and IMAG is the one obtained for the nouns $(r=.45)$. Regarding the correlations between \%CFV and the three frequency measures, they appear to be higher for the predicates than for the nouns, which means that the relation between age of acquisition and frequency is stronger for predicates than for nouns. Similar results were found for English in a large action-object picture-naming stimulus set (Szekely et al., in press).

\section{Conclusions}

The CFVlexvar.xls database puts together imageability, frequency, and grammatical characteristics of the first words acquired by Italian children as drawn from the Italian version of the MacArthur CDI (Caselli \& Casadio, 1995). For each of 519 words, the database includes values for age of acquisition, frequency in the written lexicon 
Table 4

Correlations Between \%CFV and the Other Variables, Separately for Nouns, Verbs, and Adjectives

\begin{tabular}{lcccc}
\hline$\%$ CFV & IMAG & CWFq & AWFq & ASFq \\
\hline Nouns & $.45 \dagger$ & $.27 \dagger$ & n.s. & $.24 \dagger$ \\
Verbs & $.27^{*}$ & $.42 \dagger$ & $.37 \dagger$ & $.35 \dagger$ \\
Adjectives & $.26^{*}$ & $.28^{*}$ & $.35^{*}$ & $.34^{*}$ \\
\hline
\end{tabular}

Note-\%CFV, age of acquisition; IMAG, imageability; CWFq, child written frequency; AWFq, adult written frequency; ASFq, adult spoken frequency. $* p<.05$. ${ }^{\dagger} p<.001$.

of primary school children, and frequency in the adult spoken and written lexicons, as well as new values of imageability.

From the correlational analysis, we found that the earlier a word is acquired, the likelier it is to have an easily imageable referent and to be used frequently at different ages and in different contexts (both in the spoken and written language of adults as well as in the written language of children). This finding is particularly interesting because in the sample considered here, all the words were acquired very early and were very imageable. This result therefore confirms and extends results previously reported in the literature (Barca et al., 2002; Bates et al., 2001; D’Amico et al., 2001; Ellis \& Morrison, 1998; Morrison \& Ellis, 1995). The high correlations between the three frequency measures suggest that the words of the CFV tend to be used in a similar fashion both in texts written or read by children and in the production of written and spoken adult language.

The correlations between imageability and the frequency measures are all negative, indicating that both children and adults tend to use abstract words prevailingly. Therefore, whereas very young children (up to 30 months of age) use mostly very imageable words, subsequent lexical choices and/or the types of subjects treated cause an increased incidence of less imageable words, and this holds specifically for verbs. When we split words of the CFV by grammatical category, we obtained additional data favoring the theory of the evolutionary sequence of vocabulary acquisition (see Caselli et al., 1995; Caselli et al., 1999; Colombo \& Burani, 2002; D'Amico et al., 2003; D’Odorico et al., 2001; Szekely et al., in press). Like children in other countries, Italian children seem to acquire nouns earlier and more easily than predicates (i.e., verbs and adjectives). In the CFV, there is a greater proportion of nouns in comparison with predicates. A similar difference is found in the IBV, which contains the words that should be known by the end of compulsory education, and in a dictionary of Italian (ID).

Regarding frequency, nouns seem to be used on average less frequently with respect to words of the other grammatical categories. Moreover, the nouns acquired first tend to be more imageable than verbs and adjectives acquired first. The differences in imageability between nouns and verbs have already been reported by Chiarello et al. (1999), who, in a study on English, found that referents of nouns tend to be scored as more imageable than those of verbs. Our results point in the same direction, suggesting that nouns are easier to process than verbs because they are more concrete or more imageable (see also Colombo \& Burani, 2002; Paivio, 1986).

From the correlational analysis between age of acquisition and each of the frequency measures, we found that the relation between age of acquisition and the frequency measures is stronger for verbs and adjectives than for nouns. What could cause this result? Is it simply that the first predicates acquired are used most in subsequent age ranges, or does this happen because for predicates (in contrast to nouns) there is less of a possibility of choice and we therefore end up always using the same few, from childhood to adulthood? Indeed, we would tend to use a large number of nouns, most of them only rarely, whereas we would tend to use a smaller number of predicates, each very often. This smaller lexical variability for predicates than for nouns causes predicates acquired early to be used more often than nouns acquired equally early. This happens because predicates can be used in multiple contexts, in which they can assume slightly different meanings. Nouns, however, "define" context and therefore vary depending on the subject. This possibly explains why the first acquired predicates are used more frequently than are the first acquired nouns.

In this study, the intention was to "take a photograph" of children's first vocabulary, taking a closer look at some lexical and grammatical characteristics of these words and supplying a useful instrument for this area of research.

\section{REFERENCES}

Barca, L., Burani, C., \& Arduino, L. S. (2002). Word naming times and psycholinguistic norms for Italian nouns. Behavior Research Methods, Instruments, \& Computers, 34, 424-434.

Bates, E., Burani, C., D'Amico, S., \& Barca, L. (2001). Word reading and picture naming in Italian. Memory \& Cognition, 29, 986-999.

BRYSBAERT, M. (1996). Word frequency affects naming latency in Dutch when age of acquisition is controlled. European Journal of Cognitive Psychology, 8, 185-193.

CAMAIONI, L., \& Longobardi, E. (1995). Nature and stability of individual differences in early lexical development of Italian-speaking children. First Language, 15, 203-218.

Caselli, M. C., Bates, E., Casadio, P., Fenson, J., Sanderl, L., \& WEIR, J. (1995). A cross-linguistic study of early lexical development. Cognitive Development, 10, 159-200.

Caselli, M. C., \& Casadio, P. (1995). Il primo vocabolario del bambino: Guida all'uso del questionario MacArthur per la valutazione della comunicazione e del linguaggio nei primi anni di vita [The child's first words: Guide to the use of the MacArthur questionnaire for assessing communication and language in the first years of life]. Milan: Franco Angeli.

Caselli, M. C., Casadio, P., \& Bates, E. (1999). A comparison of the transition from first words to grammar in English and Italian. Journal of Child Language, 26, 69-111.

Chiarello, C., Shears, C., \& Lund, K. (1999). Imageability and distributional typicality measures of nouns and verbs in contemporary English. Behavior Research Methods, Instruments, \& Computers, 31, 603-637.

Colombo, L., \& Burani, C. (2002). The influence of age of acquisi- 
tion, root frequency, and context availability in processing nouns and verbs. Brain \& Language, 81, 398-411.

CoRNOLDI, C. (1974). Imagery values for 310 Italian nouns. Giornale Italiano di Psicologia, 1, 211-225.

D'Amico, S., Devescovi, A., \& Bates, E. (2001). Picture naming and lexical access in Italian children and adults. Journal of Cognition \& Development, 2, 71-105.

D'Amico, S., Devescovi, A., \& Bates, E. (2003). Timed picture naming in Italian speaking children and adults: Differences between objects and actions. Manuscript submitted for publication.

De Mauro, T. (1991). Guida all'uso delle parole [A guide for the use of words] (11th ed.). Rome: Editori Riuniti.

De Mauro,T., Mancini, F., Vedovelli, M., \& Voghera, M. (1993). Lessico di frequenza dell'italiano parlato [Frequency lexicon of spoken Italian]. Milan: Etaslibri.

Devescovi, A., \& Caselli, M. C. (2001). Una prova di ripetizione di frasi per la valutazione del primo sviluppo grammaticale [A sentence repetition task assessing early grammatical development in Italian]. Psicologia Clinica Dello Sviluppo, 5, 341-364.

D'Odorico, L., Carubbi, S., Salerni, N., \& Calvo, V. (2001). Vocabulary development in Italian children: A longitudinal evaluation of quantitative and qualitative aspects. Journal of Child Language, 28, 351-372.

Ellis, A. W., \& Morrison, C. M. (1998). Real age-of-acquisition effects in lexical retrieval. Journal of Experimental Psychology: Learning, Memory, \& Cognition, 24, 515-523.

Fenson, L., Dale, P. S., Reznick, J. S., Bates, E., Thal, D. J., \& Pethick, S. J. (1994). Variability in early communicative development. Monographs of the Society for Research in Child Development, 59(Whole No. 5).

Fenson, L., Dale, P. S., Reznick, J. S., Thal, D., Bates, E., Hartung, J. P., Pethick, S., \& ReILly, S. (1993). MacArthur communicative development inventories: User's guide and technical manual. San Diego: Singular Publishing.

GoPNIK, A., \& CHOI, S. (1995). Names, relational words and cognitive development in English and Korean speakers: Nouns are not always learned before verbs. In M. Tomasello \& W. Merriman (Eds.), Beyond names for things: Young children's acquisition of verbs (pp. 63-80). Hillsdale, NJ: Erlbaum.

JoRM, A. F. (1991). The validity of word age-of-acquisition ratings: A longitudinal study of a child's word knowledge. British Journal of Developmental Psychology, 9, 437-444.

Laudanna, A., Thornton, A. M., Brown, G., Burani, C., \& MarCONI, L. (1995). Un corpus dell'italiano scritto contemporaneo dalla parte del ricevente [A new corpus of contemporary written Italian]. In S. Bolasco, L. Lebart, \& A. Salem (Eds.), III Giornate Internazionali di Analisi Statistica dei Dati Testuali [3rd International Conference on Statistical Analysis of Textual Data] (Vol. 1, pp. 103-109). Rome: CISU.

Marconi, L., Ott, M., Pesenti, E., Ratti, D., \& Tavella, M. (1994). Lessico elementare: Dati statistici sull 'italiano scritto e letto dai bambini delle elementari [Elementary lexicon: Statistical data for Italian written and read by elementary school children]. Bologna: Zanichelli.

Morrison, C. M., Chappell, T. D., \& Ellis, A. W. (1997). Age of acquisition norms for a large set of object names and their relation to adult estimates and other variables. Quarterly Journal of Experimental Psychology, 50A, 528-559.

Morrison, C. M., \& Ellis, A. W. (1995). Roles of word frequency and age of acquisition in word naming and lexical decision. Journal of Experimental Psychology: Learning, Memory, \& Cognition, 21, 116-133.
PAIVIO, A. U. (1986). Mental representations: A dual coding approach. New York: Oxford University Press.

Paivio, A. U., Yuille, J. C., \& Madigan, S. A. (1968). Concreteness, imagery, and meaningfulness values for 925 nouns. Journal of Experimental Psychology Monograph Supplement, 71, 1-9.

Szekely, A., D'Amico, A., Devescovi, A., Federmeier, K., Herron, D., IYer, G., Jacobsen, T., ArÉvalo, A. L., Vargha, A., \& BATES, E. (in press). Timed action and object naming. Cortex.

Tardif, T., Gelman, S. A., \& Xu, F. (1999). Putting the "noun bias" in context: A comparison of English and Mandarin. Child Development, 70, 620-635.

Thornton, A. M., Iacobini, C., \& Burani, C. (1997). BDVDB: Una base di dati sul vocabolario di base della lingua italiana [BDVDB: A database on the Italian basic vocabulary] (2nd ed., revised and expanded). Rome: Bulzoni.

Walley, A. C., \& Metsala, J. L. (1992). Young children's age-ofacquisition estimates for spoken words. Memory \& Cognition, 20, 171-182.

ZiNGARELli, N. (1987). Vocabolario della lingua italiana di Nicola Zingarelli [Italian dictionary by Nicola Zingarelli]. Bologna: Zanichelli.

\section{NOTES}

1. We are grateful to the authors of the cited Italian databases for allowing us to draw values for the present words.

2. Observed age-of-acquisition values of children (objective ratings) are highly correlated with ratings by adults (subjective ratings), although subjective ratings are more correlated with word frequency (Ellis \& Morrison, 1998; Morrison et al., 1997).

3. Although in this article we report only data and results pertaining to the total value of $\mathrm{CWFq}$, the database contains separate values for the lexicons of reading $(\mathrm{CCFq})$ and writing $(\mathrm{CPFq})$, in addition to the total values $(\mathrm{CWFq})$.

\section{ARCHIVED MATERIALS}

The following materials associated with this article may be accessed through the Psychonomic Society's Norms, Stimuli, and Data archive, http://www.psychonomic.org/archive/.

To access these files, search the archive for this article using the journal (Behavior Research Methods, Instruments, \& Computers), the first author's name (Rinaldi), and the publication year (2004).

FILE: Rinaldi-BRMIC-2004.zip.

DESCRIPTION: The compressed archive file contains three files:

CFVlexvar.xls, containing the norms developed in the present article, as a $89 \mathrm{~K}$ file generated by Excel 5.0 for Windows. Each row represents one of 519 words; each column, one of the variables.

Introductory page.doc, a full description of the content of the CFVlexvar database, including extended definitions of the columns of the Excel file (a $37 \mathrm{~K}$ doc file).

Acknowledgments.doc, acknowledgments to the authors of the cited Italian databases for allowing us to draw values for the words used in the present study (a $21 \mathrm{~K}$ doc file).

AUTHOR'S E-MAIL ADDRESS: c.burani@istc.cnr.it.

AUTHOR's WeB SITE: http://www.istc.cnr.it.

(Manuscript received December 19, 2003; accepted for publication May 22, 2004.) 